\title{
PENENTUAN RUTE TRANSPORTASI DENGAN METODE SAVING MATRIX PADA PG MADUKISMO, YOGYAKARTA
}

\section{DETERMINATION OF TRANSPORTATION ROUTES USING MATRIX SAVING METHOD IN PG MADUKISMO, YOGYAKARTA}

\author{
Ika Putri Rahmasari, Pandi Pardian* \\ Program Studi Agribisnis Fakultas Pertanian Universitas Padjadjaran, Bandung \\ *Email: pandi.pardian@unpad.ac.id \\ (Diterima 14-04-2020; Disetujui 15-06-2020)
}

\begin{abstract}
ABSTRAK
Peningkatan produktivitas pabrik gula (PG) salah satunya dilakukan dengan melakukan perbaikan pada kegiatan penebangan dan pengangkutan bahan baku tebu dari lahan ke pabrik tebu. PG Madukismo sudah menerapkan pola tebang angkut tebu untuk menyiapkan bahan baku untuk pabrik gula namun masih berdasarkan jadwal tebang tebu tiap daerah, namun masih memiliki kelemahan dan tidak berjalan baik. Oleh sebab itu, dilakukan penelitian lebih lanjut terkait trasportasi kegiatan tebang angkut tebu dari lahan ke pabrik gula. Tujuan dari penelitian ini adalah untuk mengetahui rute transportasi optimum dalam proses pengangkutan bahan baku tebu di PG Madukismo. Penelitian ini menggunakan analisis Saving Matrix. Hasil penelitian ini menunjukkan bahwa pengunaan metode saving matrix dalam menentukan rute transportasi pengangkutan bahan baku tebu dapat memberikan penghematan jumlah kendaraan yaitu sebanyak 222 kendaraan dengan membagi wilayah kerja PG Madukismo menjadi empat wilayah kerja sehingga terjadi peghematan jarak sebesar $373,9 \mathrm{~km}$.
\end{abstract}

Kata Kunci: Tebu, Saving matrix, Rute Transportasi, Madukismo

\section{ABSTRACT}

Increasing sugar mill productivity one of them is done by making improving the process of cutting and transportation sugarcane from the land until the sugar mill. PG Madukismo has implemented that sugarcane cutting and hauling pattern to fulfill raw material in the mill however that's not running well because it is still based on the sugarcane cutting schedule of each region, therefore, this study is conducted on based on sugarcane transportation activities. The goal of this study was to determine the optimum transportation route in the process of transporting sugarcane raw materials to PG Madukismo. This study uses saving matrix analysis. Results of this study showing that the vehicles used are 222 and 4 groups of transportation areas to provide a saving distance of $373.9 \mathrm{Km}$

Keywords: Sugarcane; Saving Matrix; Routes, Transportation; Madukismo

\section{PENDAHULUAN}

Tebu (Saccharum officinarum) merupakan salah satu tanaman jenis rumput-rumputan yang dapat dimanfaatkan air dan batangnya sebagai bahan baku utama produksi gula. Di Indonesia, gula memiliki peranan yang penting karena gula merupakan salah satu bahan pemanis yang sering dikonsumsi oleh masyarakat Indonesia serta diperlukan penggunaannya sebagai bahan baku untuk industri makanan dan minuman. 
Pentingnya gula bagi kebutuhan manusia juga telah ditetapkan dalam forum Wold Trade Organization (WTO) yang telah menetapkan tebu sebagai salah satu komoditi khusus bersama dengan komoditas pertanian lainnya seperti beras, jagung, ketela, dan kedelai.

Berdasarakan data Badan Pusat Statistika pada tahun 2018 impor gula mencapai 4,6 juta ton, jumlah ini meningkat dari tahun 2017 sebesar 4,48 juta ton. Nilai impor yang cukup tinggi menjadikan Indonesia menempati posisi pertama sebagai negara pengimpor gula terbesar di dunia pada periode 20172018. Oleh sebab itu, diperlukan upaya untuk meningkatkan produktivitas pabrik gula. Salah satu upaya yang dapat dilakukan adalah melalui pengelolaan tebang angkut. Faktor yang mempengaruhi produktivitas pada saat tebang angkut adalah kadar rendemen tebu asli yang berasal dari kebun, kebersihan tebangan pada saat tebu ditebang, dan jangka waktu antara tebu ditebang hingga tebu digiling di pabrik (Darmohardjo, 2014). Rendemen merupakan kadar kandungan gula yang terdapat di dalam batang tebu yang dinyatakan dengan persen. Bila dikatakan rendemen tebu $10 \%$, hal itu berarti $100 \mathrm{~kg}$ tebu yang digiling di pabrik gula akan diperoleh gula sebesar $10 \mathrm{~kg}$ (Kurniawan, 2018).

Selain dipengaruhi oleh kebersihan tebu rendemen, juga banyak dipengaruhi oleh lamanya tebu terpapar sinar matahari yang dapat menurunkan kandungan sukrosa pada batang tebu selama proses pengangkutan dan distribusi tebu. Aktivitas distribusi yang memiliki peran penting adalah transportasi tebu dari lahan ke pabrik gula. Pada pelaksanaan transportasi terdapat dua komponen penting yang mempengaruhi efektifitas transportasi, yaitu rute dan penjadwalan. Apabila transportasi pengangkutan bahan baku tidak berjalan lancar, maka akan terjadi keterlambatan dan dapat menimbulkan kerugian yang cukup signifikan bagi perusahaan.

Salah satu pabrik gula yang melakukan proses tebang angkut dalam memenuhi kebutuhan bahan baku tebu adalah Pabrik Gula (PG) Madukismo dan merupakan satu-satunya pabrik gula yang terdapat di Yogyakarta. Pemenuhan kebutuhan bahan baku tebu untuk proses produksi di PG Madukismo bekerja sama dengan petani tebu yang tersebar di beberapa wilayah yang ada di Yogyakarta dan Jawa Tengah. Terdapat tiga bentuk kerja sama yang dilakukan oleh PG Madukismo, yaitu Kemitraan (KMT), 
Kerja Sama Usaha (KSU), dan Tebu Rakyat Mandiri (Mandiri). Letak kebun petani tebu yang bekerja sama dengan PG Madukismo tersebar dibeberapa daerah yang dibagi menjadi lima wilayah kerja. Wilayah kerja dari PG Madukismo adalah Bantul dan Gunung Kidul (BKG), Sleman, Kulon Progo, Magelang, dan Temanggung (KMT), Purworejo dan Kebumen (PKB), dan Klaten. Wilayah kerja PG Madukismo diawasi oleh kepala rayon untuk setiap masing-masing wilayah kerja.

\section{METODE}

Penelitian ini merupakan penelitian kuantitatif yang menalisis suatu kasus di PG Madukismo, Yogyakarta. Pengumpulan data dilakukan dengan cara penelusuran arsip perusahaan, yaitu arsip yang terkait dengan penilitan yang berasal dari perusahaan. Data yang digunakan adalah peta wilayah kerja PG Madukismo dan data produksi tebu setiap wilayah. Sedangkan informasi lainnya diperoleh melalui proses wawancara dengan staf yang ada di PG Madukismo. Alat analisis yang digunakan dalam penelitian ini adalah saving matrix. Adapun tahap-tahap pengolahan data yang diperoleh adalah sebagai berikut:

\section{Mengidentifikasi matrik jarak}

Penentuan matriks jarak dapat dilakukan dengan menggunakan data mengenai jarak antara satu lokasi kebun dengan lokasi kebun lainnya dan jarak antara kebun dengan pabrik. Identifikasi martik jarak dapat dilakukan dengan menggunakan software google maps.

\section{Mengidentifikasi saving matrix}

Saving matrix dapat mempresentasikan penghematan dengan menghubungkan satu lokasi dengan lokasi lainnya dalam satu rute. Setelah diketahui jarak keseluruhan atau jarak antara pabrik dengan lokasi lainnya, maka langkah berikutnya adalah mengasumsikan bahwa setiap lokasi akan dilewati oleh satu truk. Hal ini berarti akan ada beberapa rute yang berbeda yang akan dilewati untuk tujuannya masing-masing. Penggabungan rute dapat dihitung menggunakan rumus berikut (Pujawan dan Mahendrawati, 2010):

$S(x, y)=J($ Pabrik,$x)+J($ Pabrik,$y)$

$$
-J(x, y)(1)
$$

Keterangan :

$S(x, y) \quad=$ Penghematan jarak $J($ Pabrik,$x)=$ Jarak pabrik dengan kebun $x$

$J($ Pabrik, $y)=$ Jarak pabrik dengan kebun $y$

$J(x, y) \quad=$ Jarak kebun $x$ dengan kebun $y$ 


\section{PENENTUAN RUTE TRANSPORTASI DENGAN METODE SAVING MATRIX \\ PADA PG MADUKISMO, YOGYAKARTA \\ Ika Putri Rahmasari, Pandi Pardian}

\section{Mengalokasikan wilayah kerja ke kendaraan dan rute}

Pembagian lokasi kebun ke dalam suatu rute perjalanan truk dilakukan dengan mempertimbangkan jumlah kebun dan kendaraan yang digunakan. Sebuah rute dapat dikatakan layak apabila jumlah permintaan tidak melebihi kapasitas kendaraan. Prosedur yang digunakan dalam mengelompokkan kebun yaitu berdasarkan nilai saving matrix terbesar. Apabila kapasitas kendaraan sudah maksmimal, maka prosedur tersebut akan dilakukan kembali sampai semua kebun dapat teralokasi dalam sutau rute perjalanan. Untuk mengetahui jumlah kendaraan yang dibutuhkan sebelumnya dilakukan perhitungan mengenai kebutuhan per hari pada masing-masing wilayah. Rumus yang dapat digunakan adalah:

Kebutuhan $/$ hari $=\left(\frac{\text { Produksi wilayah } x}{\text { Jumlah seluruh produktivitas })}\right.$

Setelah diketahui nilai kebutuhan tebu per hari, dihitung jumlah kendaraan pada masing-masing wilayah:

Jumlah kendaraan

$=\frac{\text { Kebutuhan/hari wilayah } x}{\text { kapasitas kendaraan } \times \text { frekuensi }}$

\section{Mengurutkan wilayah dalam rute yang terdefinisi}

Tujuan dari tahapan ini adalah membuat urutan kunjungan dalam suatu rute agar dapat diperoleh perjalanan dengan jarak terpendek.

\section{HASIL DAN PEMBAHASAN}

\section{Mengidentifikasi Matrik Jarak}

Tahap awal pada analisis saving matrix merupakan identifikasi jarak antar wilayah kerja dan jarak antara masingmasing wilayah kerja ke pabrik. Identifikasi jarak dilakukan dengan menggunakan data jarak dan google maps.

Dalam matriks jarak dapat dilihat bahwa jarak terjauh dari PG Madukismo adalah Kebumen, yaitu sebesar 100 km, sedangkan jarak terpendek dari PG Madukismo adalah Bantul sebesar 6,9 $\mathrm{km}$. Jarak terpendek antar wilayah adalah antara Bantul dan Sleman, yaitu sebesar $26 \mathrm{~km}$. Jarak terjauh antar wilayah adalah Klaten dengan Kebumen yaitu sebesar $145 \mathrm{~km}$. 
Tabel 1. Matrix Jarak Wilayah PG Madukismo (km)

\begin{tabular}{|c|c|c|c|c|c|c|c|c|c|c|}
\hline Dari & Pabrik & $\mathbf{A}$ & B & C & D & $\mathbf{E}$ & $\mathbf{F}$ & $\mathbf{G}$ & $\mathbf{H}$ & I \\
\hline Pabrik & 0 & & & & & & & & & \\
\hline $\mathbf{A}$ & 6,9 & 0 & & & & & & & & \\
\hline B & 51 & 49 & 0 & & & & & & & \\
\hline $\mathrm{C}$ & 21 & 26 & 55 & 0 & & & & & & \\
\hline D & 28 & 30 & 78 & 38 & 0 & & & & & \\
\hline $\mathbf{E}$ & 52 & 58 & 94 & 42 & 50 & 0 & & & & \\
\hline $\mathbf{F}$ & 76 & 81 & 118 & 66 & 74 & 33 & 0 & & & \\
\hline $\mathbf{G}$ & 65 & 62 & 105 & 56 & 41 & 57 & 65 & 0 & & \\
\hline $\mathbf{H}$ & 100 & 97 & 142 & 110 & 77 & 99 & 107 & 42 & 0 & \\
\hline I & 47 & 52 & 41 & 37 & 72 & 78 & 98 & 91 & 145 & 0 \\
\hline
\end{tabular}

Keterangan:

Pabrik : PG Madukismo

A : Wilayah Bantul

$\begin{array}{ll}\mathrm{C} & \text { : Wilayah Sleman } \\ \mathrm{F} & \text { : Wilayah Temanggung }\end{array}$

D : Wilayah Kulon Progo

B : Wilayah Gunung Kidul

G : Wilayah Purworejo

E : Wilayah Magelang

: Wilayah Klaten

$\mathrm{H}$ : Wilayah Kebumen

\section{Mengidentifikasi Saving Matrix}

Setelah mengidentifikasi matrik jarak, langkah yang dilakukan selanjutnya adalah menghitung saving matrix. Pada mulanya diasumsikan bahwa setiap wilayah akan dialokasikan dalam tiap kendaraan maka akan terdapat 9 rute. Tetapi pada perhitungan saving matrix akan terdapat pengabungan tujuan dalam satu rute, maka akan diperoleh penghematan jarak dengan menggunakan rumus persamaan (1). Sebagai contoh dari rumus persamaan (1), penghematan jarak antara dua rute yaitu rute $\mathrm{A}$ dan rute $\mathrm{B}$ (rute $\mathrm{A}=$ Pabrik-Bantul-Pabrik, dan rute $\mathrm{B}=$ Pabrik-Gunung Kidul-Pabrik). Dilakukan perhitungan sebagai berikut:

$\mathrm{S}(\mathrm{A}, \mathrm{B})=6,9+51-49=8,9$
Keterangan:

$\mathrm{S}(\mathrm{A}, \mathrm{B})=$ Penghematan jarak dari A ke B $\mathrm{J}(\mathrm{P}, \mathrm{A})=\mathrm{Jarak}$ dari pabrik ke $\mathrm{A}=6,9 \mathrm{~km}$ $\mathrm{J}(\mathrm{P}, \mathrm{B})=$ Jarak dari pabrik ke $\mathrm{B}=51 \mathrm{~km}$ $\mathrm{J}(\mathrm{A}, \mathrm{B})=\mathrm{Jarak}$ dari $\mathrm{A}$ ke $\mathrm{B}=49 \mathrm{~km}$

Setelah ditemukan nilai saving matrix pada masing-masing wilayah, kemudian nilai saving matrix tersebut diurutkan.

Berdasarkan nilai penghematan terbesar. Pada penelitian ini nilai penghematan terbesar adalah penggabungan rute $H$ dan $G$ yaitu Kebumen dan Purworejo. Hal ini dikarenakan letak dua wilayah tersebut yang saling berdampingan. 
Tabel. 2. Saving Matrix pada wilayah PG Madukismo (km)

\begin{tabular}{|c|c|c|c|c|c|c|c|c|c|}
\hline Dari & $\mathbf{A}$ & B & C & D & $\mathbf{E}$ & $\mathbf{F}$ & $\mathbf{G}$ & H & I \\
\hline $\mathbf{A}$ & 0 & & & & & & & & \\
\hline B & 8,9 & 0 & & & & & & & \\
\hline C & 1,9 & 17 & 0 & & & & & & \\
\hline D & 4,9 & 1 & 11 & 0 & & & & & \\
\hline $\mathbf{E}$ & 0,9 & 9 & 31 & 30 & 0 & & & & \\
\hline $\mathbf{F}$ & 1,9 & 9 & 31 & 30 & 95 & 0 & & & \\
\hline G & 9,9 & 11 & 30 & 52 & 60 & 76 & 0 & & \\
\hline H & 9,9 & 9 & 11 & 51 & 53 & 69 & 123 & 0 & \\
\hline I & 1,9 & 57 & 31 & 3 & 21 & 1 & 21 & 2 & 0 \\
\hline
\end{tabular}

Alokasi wilayah kerja ke kedaraan dan rute

Pengalokasi wilayah kerja ke dalam kendaraan dan rute dilakukan berdasarkan pertimbangan kapasitas kendaraan yang digunakan oleh PG Madukismo, yaitu sebesar $60 \mathrm{Ku}$. Analisa kebutuhan tebu per hari, jumlah kendaraan, dan jumlah perjalanan truk masing-masing wilayah selama musim giling.

Tabel 3. Penetapan kebutuhan tebu/hari dan jumlah kendaraan pada wilayah PG Madukismo

\begin{tabular}{cccc}
\hline Wilayah & $\begin{array}{c}\text { Produksi } \\
(\mathbf{K u})\end{array}$ & $\begin{array}{c}\text { Kebutuhan } \\
\text { /hari }(\mathbf{K u})\end{array}$ & $\begin{array}{c}\text { Jumlah } \\
\text { Kendaraan }\end{array}$ \\
\hline A & 429.616 & 12.358 & 69 \\
B & 58.782 & 1.691 & 14 \\
C & 250.444 & 7.206 & 40 \\
D & 183.788 & 5.287 & 29 \\
E & 117.462 & 3.384 & 28 \\
F & 56.965 & 1.639 & 14 \\
G & 58.391 & 1.680 & 14 \\
H & 20.286 & 508 & 4 \\
I & 40.830 & 1.174 & 10 \\
\hline Total & $\mathbf{1 . 2 1 6 . 8 2 0}$ & $\mathbf{3 5 . 0 0 0}$ & $\mathbf{2 2 2}$ \\
\hline & & &
\end{tabular}

Dari nilai produksi selama satu musim giling dapat diperoleh jumlah kendaraan yang dibutuhkan selama satu hari pengangkutan, yaitu 222 unit. Sedangkan total jumlah kebutuhan/hari pada masing-masing wilayah memiliki nilai sebesar $35.000 \mathrm{Ku}$. Nilai ini disesuaikan dengan kebutuhan bahan baku tebu di pabrik setiap harinya. Dari nilai produksi juga akan diperoleh muatan sisa pada masing-masing wilayah yang tidak dapat terangkut. Muatan sisa ini dapat menjadi dasar pertimbangan dalam menentukan rute selanjutnya.

Tabel 4. Alokasi Wilayah ke dalam rute dan kendaraan

\begin{tabular}{cccc}
\hline Wilayah & $\begin{array}{c}\text { Produksi } \\
(\mathbf{K u})\end{array}$ & $\begin{array}{c}\text { Jumlah } \\
\text { Trip }\end{array}$ & $\begin{array}{c}\text { Muatan } \\
\text { Sisa (Ku) }\end{array}$ \\
\hline A & 429.616 & 7160 & 16 \\
B & 58.782 & 979 & 42 \\
C & 250.444 & 4174 & 4 \\
D & 183.788 & 3063 & 8 \\
E & 117.642 & 1960 & 42 \\
F & 56.965 & 949 & 25 \\
G & 58.391 & 973 & 11 \\
H & 20.286 & 338 & 6 \\
I & 40.830 & 630 & 30 \\
\hline
\end{tabular}


Setelah menghitung nilai muatan sisa yang menjadi dasar pertimbangan pada pemilihan rute, selanjutnya menggabungkan beberapa wilayah ke dalam satu rute. Penggabungan dilakukan tanpa melebihi kapasitas pengangkutan truk yaitu sebesar $60 \mathrm{Ku}$.

Tabel 5. Muatan gabungan pada rute

\begin{tabular}{ccc}
\hline Rute & Tujuan & $\begin{array}{c}\text { Muatan Gabungan } \\
(\text { Ku) }\end{array}$ \\
\hline Rute 1 & A-B & 58 \\
Rute 2 & C-E & 46 \\
Rute 3 & D-F-G-H & 50 \\
Rute 4 & I & 30 \\
\hline
\end{tabular}

Dari perhitungan di atas dapat diperoleh empat rute untuk distribusi bahan baku tebu PG Madukismo. Empat rute baru tersebut, yaitu:

Rute 1 : Bantul dan Gunung Kidul

Rute 2 : Sleman dan Magelang

Rute 3 : Kulonprogo, Temanggung,

Kebumen, Purworejo, Kebumen

Rute 4 : Klaten

Penggabungan rute dilakukan dengan memperhatikan jumlah muatan sisa pada wilayah yang telah dimasukkan kedalam satu rute. Sehingga muatan sisa yang digabung dapat diangkut dengan menggunakan satu truk sampai ke pabrik.

\section{Mengurutkan wilayah dalam rute yang} terdefinisi

Setelah menggabungkan wilayah dalam rute dan kendaraan maka dilakukan pengurutan rute wilayah yang sudah digabung. Pengurutan rute ini bertujuan untuk meminimumkan jarak perjalanan yang dilalui truk. Karena apabila urutan kunjungan rute berbeda, maka jarak yang ditempuh juga akan berbeda. Pengurutan kunjungan wilayah ke dalam rute berfungsi untuk menentukan wilayah pertama yang dikunjungi hingga wilayah terakhir yang perlu dikunjungi dengan mempertimbangkan jarak terpendek. Pengurutan dilakukan dengan menggunakan semua kemungkinan yang ada pada setiap urutan huruf dengan kunjungan awal dan akhir merupakan pabrik. Kemudian dilakukan penjumlahan pada setiap rute untuk masing-masing tempat yang dikunjungi. Pengurutan dilakukan sampai tidak ditemukan kemungkinan lain dari urutan kunjungan yang dilakukan.

Tabel 6. Pengurutan rute kunjungan setiap wilayah

\begin{tabular}{|c|c|c|c|c|}
\hline Rute & Tujuan & $\begin{array}{c}\text { Muatan } \\
\text { Gabungan } \\
(\mathrm{Ku})\end{array}$ & Urutan Rute & Jarak \\
\hline \multirow{2}{*}{1} & \multirow{2}{*}{ A-B } & \multirow{2}{*}{58} & P-A-B-P & 106,9 \\
\hline & & & P-B-A-P & 106,9 \\
\hline \multirow{2}{*}{2} & \multirow{2}{*}{ C-E } & \multirow{2}{*}{46} & P-C-E-P & 115 \\
\hline & & & P-E-C-P & 115 \\
\hline \multirow{7}{*}{3} & \multirow{7}{*}{ D-F-G-H } & \multirow{7}{*}{50} & P-D-F-G-H-P & 309 \\
\hline & & & P-F-D-G-H-P & 333 \\
\hline & & & P-D-F-H-G-P & 316 \\
\hline & & & P-F-D-H-G-P & 334 \\
\hline & & & P-F-G-H-D-P & 288 \\
\hline & & & P-F-H-D-G-P & 366 \\
\hline & & & P-F-H-G-D-P & 294 \\
\hline
\end{tabular}




\begin{tabular}{|c|c|c|c|c|}
\hline Rute & Tujuan & $\begin{array}{c}\text { Muatan } \\
\text { Gabungan } \\
\text { (Ku) } \\
\end{array}$ & Urutan Rute & Jarak \\
\hline & & & P-H-D-F-G-P & 381 \\
\hline & & & P-H-F-D-G-P & 387 \\
\hline & & & P-H-G-D-F-P & 333 \\
\hline & & & P-H-G-F-D-P & 309 \\
\hline & & & P-D-G-H-F-P & 294 \\
\hline & & & P-D-H-G-F-P & 288 \\
\hline & & & P-G-H-D-F-P & 334 \\
\hline & & & P-G-D-F-H-P & 387 \\
\hline & & & P-G-F-D-H-P & 381 \\
\hline & & & P-G-D-H-F-P & 366 \\
\hline & & & P-D-G-F-H-P & 341 \\
\hline & & & P-D-H-F-G-P & 342 \\
\hline & & & P-F-G-D-H-P & 359 \\
\hline & & & P-H-D-G-F-P & 359 \\
\hline & & & P-H-F-G-D-P & 341 \\
\hline & & & P-G-H-F-D-P & 316 \\
\hline & & & P-G-F-H-D-P & 342 \\
\hline 4 & I & 30 & P-I-P & 94 \\
\hline
\end{tabular}

Berdasarkan urutan rute pengangkutan pada tabel di atas, maka dapat ditentukan rute pengangkutan yang optimal pada masing-masing rute gabungan. Penggabungan dilakukan dengan menentukan jarak terpendek dari setiap urutan kunjungan yang dicari sehingga ditemukan rute optimal berdasarkan kunjungan dengan jarak terpendek dan nilai penghematan terbesar tanpa melebihi kapasitas pengangkutan truk yang digunakan oleh PG Madukismo.
Tabel 7. Urutan Rute Optimal

\begin{tabular}{|c|c|c|c|c|}
\hline Rute & $\begin{array}{c}\text { Urutan } \\
\text { Rute }\end{array}$ & $\begin{array}{l}\text { Jarak } \\
(\mathbf{K m})\end{array}$ & $\begin{array}{c}\text { Savings } \\
(\mathrm{km})\end{array}$ & $\begin{array}{c}\text { Kapasitas } \\
(\mathbf{K u})\end{array}$ \\
\hline 1 & P-A-B-P & 106,9 & 8,9 & 58 \\
\hline 2 & P-C-E-P & 115 & 115 & 46 \\
\hline 3 & $\begin{array}{c}\text { P-F-H-G- } \\
\text { D-P }\end{array}$ & 288 & 250 & 50 \\
\hline 4 & P-I-P & 94 & - & 30 \\
\hline
\end{tabular}

Keterangan:

P: PG Madukismo, A: Wilayah Bantul,

B: Wilayah Gunung Kidul, C: Wilayah Sleman,

D: Wilayah Kulonprogo, E: Wilayah Magelang,

F: Wilayah Temanggung, G: Wilayah Purworejo,

H: Wilayah Kebumen, I: Wilayah Klaten

Berdasarkan tabel di atas, maka dapat dilihat urutan kunjungan pada setiap rute. Dengan penggunaan saving matrix maka dapat diperoleh hasil dengan jarak tempuh yang paling minimum. Total nilai penghematan yang diperoleh dari pengggunaan saving matrix adalah sebesar $373,9 \mathrm{~km}$.

\section{KESIMPULAN DAN SARAN}

\section{Kesimpulan}

Penggunanan metode saving matrix menghasilkan rute usulan dengan jalur optimum yaitu dengan mengubah lima wilayah kerja pada PG Madukismo menjadi empat wilayah kerja dan menjadi 4 rute dengan kebutuhan truk sebanyak 222 dan total penghematan jarak sebesar $373,9 \mathrm{~km}$. 
Saran

Perlu dilakukan penelitian dan analisis lebih mendalam mengenai penentuan rute distribusi bahan baku tebu berdasarkan jadwal tanam hingga jadwal panen.

\section{UCAPAN TERIMA KASIH}

Terimakasih yang sebesarnya diucapkan kepada pihak PG. Madukismo yang dengan terbuka menerima dan membantu terlaksannya kegiatan penelitian.

\section{DAFTAR PUSTAKA}

Badan Pusat Statistik. (2017). Produksi Komoditi Indonesia. Jakarta

Creswell, J.W. (2009). Research Design: Qualitative, Quantitative, and Mixed Methods Approaches. Newbury Park: Sage Publication.

Direktorat Jendral Pertanian. (2017). Outlook Tanaman Pangan dan Hortikultura. Jakarta: Direktorat Jendral Hortikultura Kementrian Pertanian Indonesia.

Hakim, A. (2006). Manajemen Industri. Yogyakata: CV. Andi Offset

Heizer, J., dan Render, B. (2010). Manajemen Operasi. Buku 2. Edisi 9. Jakarta: Salemba Empat.

Herjanto, E. (2007). Manajemen Operasi. Edisi 3. Jakarta: PT. Grasindo.

Lincoln, G. (1985). Naturalistic Inquiry. Edition 1. Beverly Hills: Sage Publication.

Arifin, B. (2008). Ekonomi Swasembada Gula Indonesia. Economic Review 211(211):1-12.

Ananda, M. S., Sukmawati, A., Syamsun, M., \& Ali, A. (2016).
Pengembangan Model Peningkatan Kompetensi Pekerja Domestik Indonesia di Malaysia, Journal of Technology Management, 15(3), 262-278.

http://doi.org/10.12695/jmt.2016.15 .3 .4

Hudori, M. dan Madusari, M. (2017). Penentuan Rute Angkutan Tandan Buah Segar (TBS) Kelapa Sawit yang Optimal dengan Metode Saving Matrix. Jurnal Citra Widya Edukasi, 9(1) 25-39.

Kurniawan, I.E. and Purwono. (2018). Tebang, Muat dan Angkut di Wilayah PG Madukismo, Yogyakarta. Buletin Agrohorti, 6(3): 354-361.

Rushton, Alan, Phil Croucher, and Peter Baker. (2006). The Handbook of Logistics and Distribution Management. Project Management Journal, 40:664.

Sutaryanto, T. (2009). Pentingnya Peningkatan Mutu Tebu. Jurnal Gula Indonesia, 33(2): 60-71.

Thoriq, A. dkk. (2017). Studi Siklus Waktu Proses Muat Angkut Tebu Secara Mekanis di PG jatitujuh, Majalengka, Jawa Barat. Jurnal Teknologi Pertanian, 11(1): 62-67.

Nitiadiwidojo, T. (1984). Pelaksanaan Proyek Panduan Siprab Tahun Giling 1983 di PG Tulangan. Preceedings Diskusi Teknis dan Ilmiah. Pasuruan: Balai Penelitian Perusahaan Perkebunan Gula. Pp 166.

Harison, G.I. 2012. Sistem Penunjang Keputusan Penjadwalan Transportasi Angkut Tebu (Studi Kasus PG, Rajawali IIi Unit Jatitujuh, Majalengka). Institut Pertanian Bogor. Bogor. 